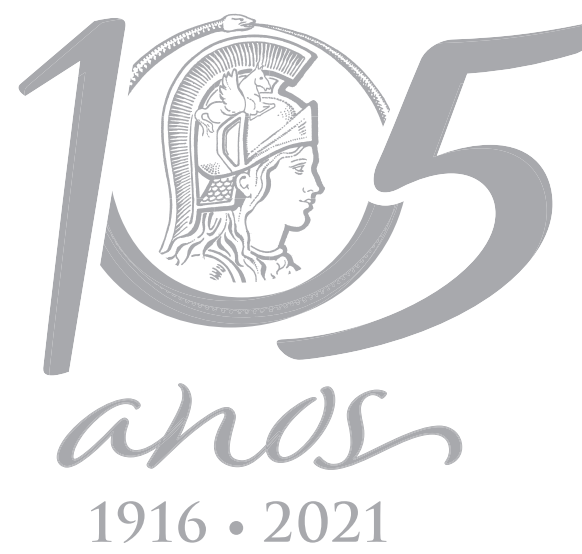

\title{
GEOSCIENCES
}

\section{High-resolution semi-automatic mapping based on an Unmanned Aerial Vehicle (UAV) to capture geological structures}

\author{
JULIO A. MOREIRA, FABRICIA B. DE OLIVEIRA, CARLOS H.R. DE OLIVEIRA, ALVARO \\ C. FIGUEIREDO, MAURO C.L. FILHO \& EDUARDO B. DUARTE
}

\begin{abstract}
Due to the recent technological progress, Unmanned Aerial Vehicles (UAV), is an alternative for the high-resolution imaging of the terrestrial surface, helping map lineaments, essential structures on the stage of geological mapping. Therefore, this research aims to accomplish and to confirm the efficiency of the use of UAV highresolution imaging for semi-automatic lineament mapping, in a shear zone in Guaçuí/ES. Orthomosaic was created from the UAV imaging, in which the LINE algorithm was used from Geomath PCl software for the semi-automatic mapping of lineaments. In addition, a manual lineament mapping was performed on the orthomosaic for comparison purposes, and a shaded relief image was made up of Azimuth $135^{\circ}$ and Elevation $45^{\circ}$, from the SRTM data, followed by manual lineament mapping for a regional vision of the studied area. On the semi-automatic and manual extraction on the orthomosaic and shaded relief image, $61.30 \%, 61.63 \%, 57.38 \%$ of the lineaments, respectively, have NW-SE direction, showing a really strong correlation. Therefore, the semi-automatic mapping is extremely effective in terms of structural trends acquisition and can provide fine-scale data for the assessment of inaccessible areas.
\end{abstract}

Key words: geological mapping, geotechnologies, structural geology, remote sensing.

\section{INTRODUCTION}

The knowledge of brittle geological structure, like faults and fractures represented by lineaments, is extremely important from scientific and economic point of view, including geological mapping, mineral exploration, aquifers viability and identification of tectonic events (Silva et al. 2016, Aretouyap et al. 2020).

According to CPRM (2017), lineament is an isolated feature or a set of topographic features, with tonality variation of an image or of a topographic map, that presents itself as an alignment and reflects elements of the geological structure, such as faults, fractures, direction of layers and belt of shearing. The precision of identification and interpretation of these lineaments depends on the image quality that is to be interpreted. Orthomosaics and digital models of elevation are supplies normally used on photo interpretation (Raj et al. 2017, Das et al. 2018, Sharifi et al. 2018, Javhar et al. 2019).

Considering the recent technological progress, Unmanned Aerial Vehicles (UAVs), is an alternative on the acquisition of the terrestrial surface images, presenting major benefits when compared to other methods, like lower cost, higher ease of operation and mostly the possibility of generating high resolution images in real time (Crommelinck et al. 2016, Dong et al. 2020, Karantanellis et al. 2020). 
The photogrammetry is a technique that captures information of a particular object from two or more photographs taken in different angles. Structure from Motion (SfM) is a photogrammetric technique in which orientation and position of the camera is automatically corrected using overlapped images (Jiang et al. 2020). Points of spatial reference on the different images that correspond to real objects of the landscape are matched (matching) to build clouds with points in three dimensions (3D), and from these clouds they generate surface models and orthomosaics or textured surfaces (Snavely et al. 2007, Vasuki et al. 2014).

Studies using photogrammetric and remote sense data have been used to automatically map and measure geological structures. Conceição \& Silva (2013) conducted a study that tested the application of images from satellites and of digital models of elevation on the automatic lineaments identification, obtaining consistent results. Vasuki et al. (2014), from high spatial resolution pictures ( 1 pixel $\approx 1 \mathrm{~cm}^{2}$ ), captured by UAV, generated a map of geological structures and calculated its respective orientations using a semi-automatic method, achieving a maximum error of $4.4^{\circ}$ when compared to the field data collected.

The visual interpretation of lineaments is subjective and demands a lot of time from a specialist, which shows that the major benefits of automatic or semi-automatic lineament detection methods are speed and reproducibility (Zhao et al. 2018, Soliman \& Han 2019). However, automatic methods often identify lineaments that are not related to geological structures, like roads and fences. Thus, the automatic methods significantly identify more lineaments than the study area actually presents. Another limitation is that a single structure can be identified as a series of segments. Therefore, these limitations reveal that to create a good structural map it is necessary some level of interaction by the user (Sarp 2005, Abdullah et al. 2013).

The study area is located in the south region of the state of Espirito Santo, in the city of Guaçuí, which was chosen for having strong tectonic influence, in a shear zone. According to Arcanjo (2011), these areas develop an infinity of fault and fracture plans, presenting usually linear strips, being able to reach hundreds of meters in several kilometers long. The large amount of lineaments contained in a narrow linear strip is the main characteristic of the area in orbital and aerial images, since it extends all 320 km. Guaçuí Shear Zone marks the late collisional period of Orógeno Araçuaí and, since it is a compression area, several structures were formed like fractures and foliation plans (Calegari et al. 2016, Gouvêa et al. 2020, Hartwig et al. 2020), that can be observed through UAV imaging.

Thus, this research aims to accomplish and prove the efficiency of semi-automatic lineament mapping, from high resolution UAV imaging, in a shear zone.

\section{MATERIALS AND METHODS}

The methods of this study are summarily described on the flowchart of Figure 1.

\section{Phase 1}

High resolution images obtained by the UAV Phantom 4 from DJI manufacturer were used and their main characteristics are described in Table I. Digital model of surface was generated from images of the Shuttle Radar Topografic Mission (SRTM). The images captured by UAV were georeferenced from three control points obtained in solo, by means of topographic GPS receptor brand Magellan, Promark 3 model, which were discharged on GNSS software 


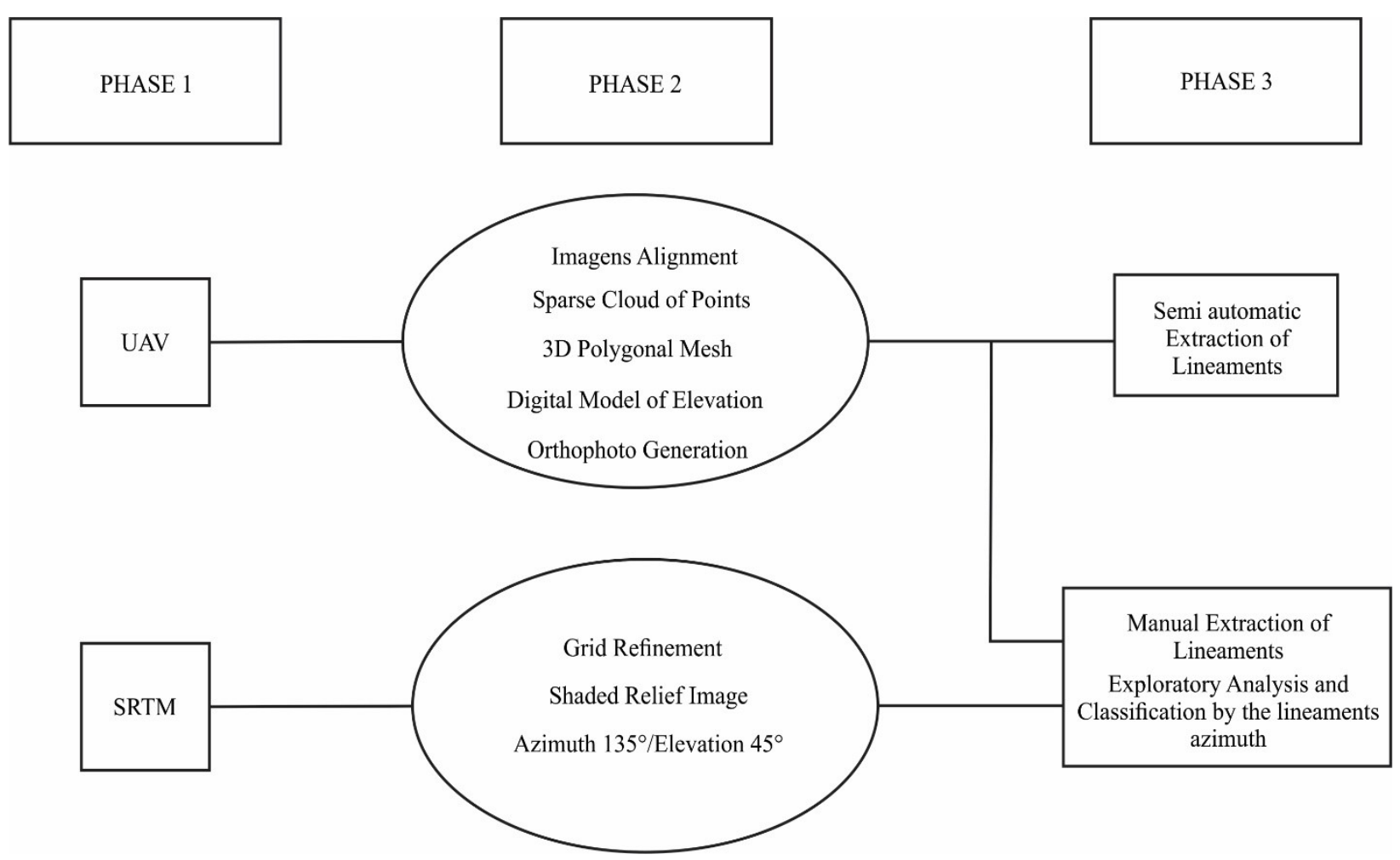

Figure 1. Flowchart of the methodology employed.

solutions 3.8 and post-processed by the Precise Point Positioning (PPP), supplied by the Brazilian Institute of Geography and Statistics (IBGE). The SRTM data were obtained at no charge through the siege of USGS (2017).

\section{Phase 2}

\section{UAV}

A selection of photographs was realized, with the purpose of reducing possible mistakes made during the data processing, images with high rotation in relation to the previous and with natural lighting problems were eliminated. The images were obtained on May 26th of 2017, with centimeter spatial resolution on the visible spectrum range.

For the digital processing of data obtained by UAV it was used the Agisoft Photoscan 1.2.0 software, where the images alignment was executed through the correlation of the properly oriented and overlapped images, in which the algorithm searches for common points on the images and combines them, finding the camera position in each image and refining its calibration parameters, generating a sparse cloud of points. Afterwards, a 3D polygonal mesh with the algorithm of the software called "height/ terrain map" was generated, that was texturized in order to obtain a better view on the digital model of elevation. The orthomosaic was generated, corrected from geometric deformations. Every stage used quality and precision parameters, available on the software, considerably increasing its processing time.

\section{SRTM}

After the cutting of image regarding the study area, it was initiated the processing of SRTM data on the software GIPSY 5.4.1 (Georeferenced 
Table I. Main particularities of UAV Phantom 4 (DJI 2017).

\begin{tabular}{|c|c|c|c|c|}
\hline Sensor & Lenses & Weight & Diagonal Size & Maximum Flight Time \\
\hline $\begin{array}{c}1 / 2,3^{\prime \prime} \mathrm{CMOS} \\
\text { effective pixels: } 12,4 \\
M\end{array}$ & $\begin{array}{c}\text { FOV } 94^{\circ} 20 \mathrm{~mm}(35 \mathrm{~mm} \text { format } \\
\text { equivalent } \mathrm{f} / 2,8, \text { focus at } \infty\end{array}$ & $1380 \mathrm{~g}$ & $1380 \mathrm{~g}$ & $28 \mathrm{~min}$ \\
\hline
\end{tabular}

Subtitles: CMOS = complementary metal-oxide-semiconductor; FOV = Field of view.

Information Processing System - INPE). The SRTM images have spatial resolution of $90 \mathrm{~m}$. From the rectangular grid with bicubic interpolation generation its resolution refined to $10 \mathrm{~m}$, to improve its spatial resolution and then it was generated a shaded relief image with azimuth of $135^{\circ}$, elevation of $45^{\circ}$ and relief exaggeration of 6.34 .

\section{Phase 3}

\section{Semi-automatic extraction of lineaments}

The semi-automatic extraction of lineaments on the orthomosaic generated by UAV initiated on the $\mathrm{PCl}$ Geomatica 8.2 software through the LINE algorithm, that transforms linear features, present on the images, in a vector, in an automatic way. As an input, the algorithm needs a singular conduit of an image, and therefore Band-1 (wavelength among 625-740 nm) was used. The image was firstly dimensioned to 8-bit using a routine of nonlinear dimensioning. The output is controlled by the following global parameters: Filter Radius (FR), Edge Gradient Threshold (EGT), Curve Length Threshold (CLT), Line Fitting Error Threshold (LFET), Angular Difference Threshold (ADT), Linking Distance Threshold (LDT).

$F R$ relates to the radius of the edge detection filter in pixels and defines what level the algorithm identifies the information as a lineament, having as standard value 10. EGT defines the level limit of a edge pixel minimum gradient with the purpose to obtain a binary image, and therefore the pixels above the threshold will represent an edge element on the binary image, its standard value is 100. CLT defines the minimum length of curve for a determined element to be considered a lineament, in pixels, having as a standard value 30 pixels. LFET establishes the maximum allowed error when overlapping a line on a curve, in which lower values promote a better setting, although shorter segments on the lines, having as standard value 3 . ADT specifies a maximum angle among segments of a line in degrees, in other words, if the angle exceeds the established maximum, the line divides itself in two or more vectors, in addition, this angle also refers to the maximum angle between two vectors to be connected, having 30 as a standard value. LDT defines a minimum distance between the final points of two vectors to be connected, in pixels, its standard value is 20 .

The values specified in global parameters of this work were based on the works of Conceição \& Silva (2013), Kocal et al. (2004) and Thannoun (2013). They were used as a reference to establish new values, considering the characteristics of the orthomosaic generated by UAV and the geology of the imaged area. In Table II are the values that the authors mentioned above, and the values tested in the present work. Editing of some lineaments extracted by the algorithm was done and due to that it is a semi-automatic extraction. 
Table II. The input parameters used as reference and the one tested in this research.

\begin{tabular}{|c|c|c|c|c|}
\hline Parameters & $\begin{array}{c}\text { Conceição \& Silva } \\
\text { (2013) }\end{array}$ & $\begin{array}{c}\text { Kocal et al. } \\
\text { (2004) }\end{array}$ & $\begin{array}{c}\text { Thannoun } \\
\text { (2013) }\end{array}$ & Tested in the Work \\
\hline FR & 15 & 12 & 5 & 15 \\
\hline EGT & 60 & $25-60$ & 75 & 80 \\
\hline CLT & 10 & $20-30$ & 10 & 20 \\
\hline LFET & 5 & 3 & 2 & 15 \\
\hline ADT & 15 & 20 & 20 & 45 \\
\hline LDT & 30 & 1 & 1 & 5 \\
\hline
\end{tabular}

\section{Manual extraction of lineaments}

The manual extraction of lineaments on the orthomosaic generated by UAV was necessary to enable the evaluation of LINE algorithm performance. Its main advantage is the greater ease in detecting the non-geological lineaments with the human eye. The extraction of lineaments scale was 1:50, demarking the present fractures and faults.

The manual extraction of the lineaments on the SRTM images was due to the fact that it enables an analysis not only local from the studied area, being able to correlate the present regional geological features. Its extraction scale was given in the scale of 1:150.000, marking the valleys present on the demarcated area.

\section{Exploratory analysis and classification by the lineament's azimuth}

From the automatic extraction of the orthomosaic and manually of the two images, its exploratory analysis and classification was performed according to its azimuth. The exploratory analysis was generated on the GIPSY 5.4 .1 software from the confection of rosettes and histograms. For the azimuth classification it was used the Easy Calculate tool from ArcGis 10.3 software, in which the lineaments were gathered in four azimuthal classes: N-S, E-W, NE-SW (includes NNE-SSW and ENE-WSW) and NW-SE (includes NNW-SSE and WNW-ESSE). Its intervals are indicated on Figure 2.

\section{RESULTS AND DISCUSSION}

It was obtained a sparse cloud with 66,501 points (Figure 3a) with the alignment process of 51 photographs, that were then interpolated to obtain a dense cloud with 116,110,416 points (Figure 3b), containing higher density of information about the imaged area.

The 3D polygonal mesh generated $14,576,549$ triangular faces, distributed in 7,293,000 vertices (Figure 4). In relation to the veracity of representation of the imaged area, strongly characterized by the presence of metamorphic foliations and prominent fractures/faults, the algorithm used by the software has showed itself as extremely viable, because it represents these structures on the terrain. Afterwards the planialtimetric correction of the generated products, through the ground control points, it was obtained the digital model of elevation DME (Figure 5a) and orthomosaic (Figure 5b).

The automatic extraction on the orthomosaic generated by UAV resulted in a total of 19,079 lineaments (Figure 6). This overly high value is 
explained by the fact that the LINE algorithm is based on edge identification, still not having a pattern to distinguish linear features associated to geological structures from the ones that result from the abrupt tonality difference. In addition, sometimes, the algorithm separates the lineament in several line segments, that in truth would be a single one, raising even more the amount of extracted lineaments. On the manual extraction of lineaments from the same orthomosaic, it was generated a total of 318 lineaments (Figure 7), a lower number that can be explained by the fact that the problems mentioned above do not happen, although with a realization time way higher. On the shaded relief image, it was extracted 305 lineaments on total (Figure 8).

From the extracted linear features, it was generated directional maps of the automatically extracted features (Figure 9) and manually on the orthomosaic (Figure 10), and manually

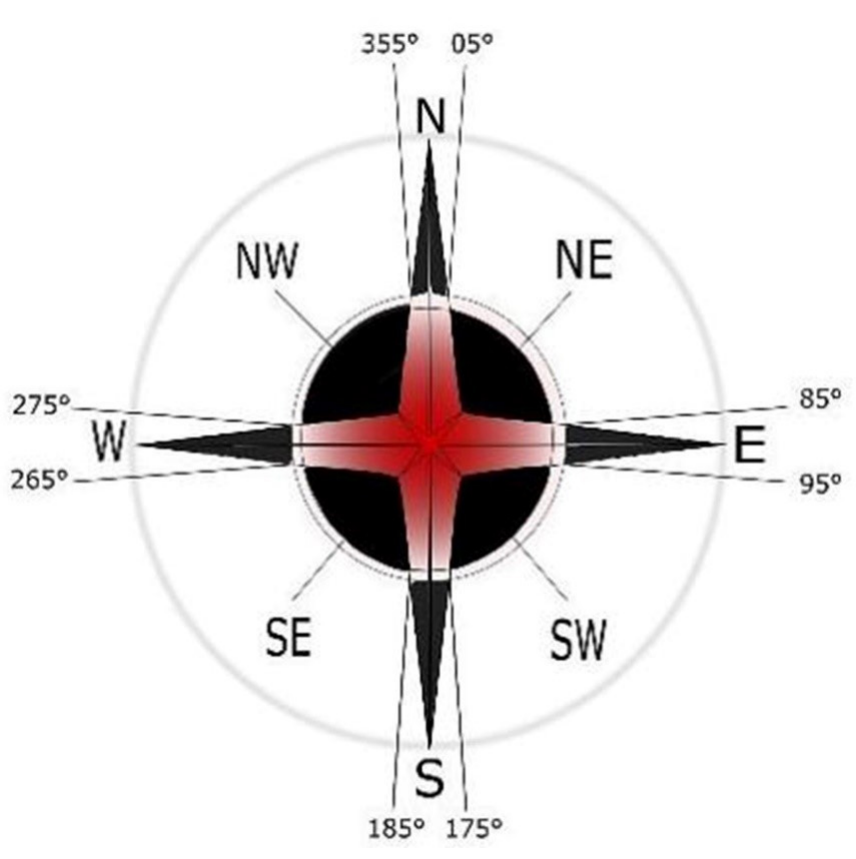

on the shaded relief image (Figure 11). The direction NW-SE was dominant, with $61.30 \%$ (Table III), 61.63\% (Table IV) and 57.38\% (Table $\mathrm{V}$ ), respectively, followed by the direction NE-SW, in every image, revealing the strong correlation among all of them, as much locally between two tested methods on the orthomosaic, as regionally from the data of the shaded relief image. The linear features extracted from the orthomosaic generated by UAV such as manually as automatically, had directions between N20W and N40W its lineaments predominance (Figure $12 \mathrm{a}, \mathrm{b})$, different from the regional image in which the direction between N50W and N60W was the predominant (Figure 12C), still with high rate of lineament with direction between N20W and N40W.

Figure 2. Illustration of ranges of azimuthal classes adopted in this research. 

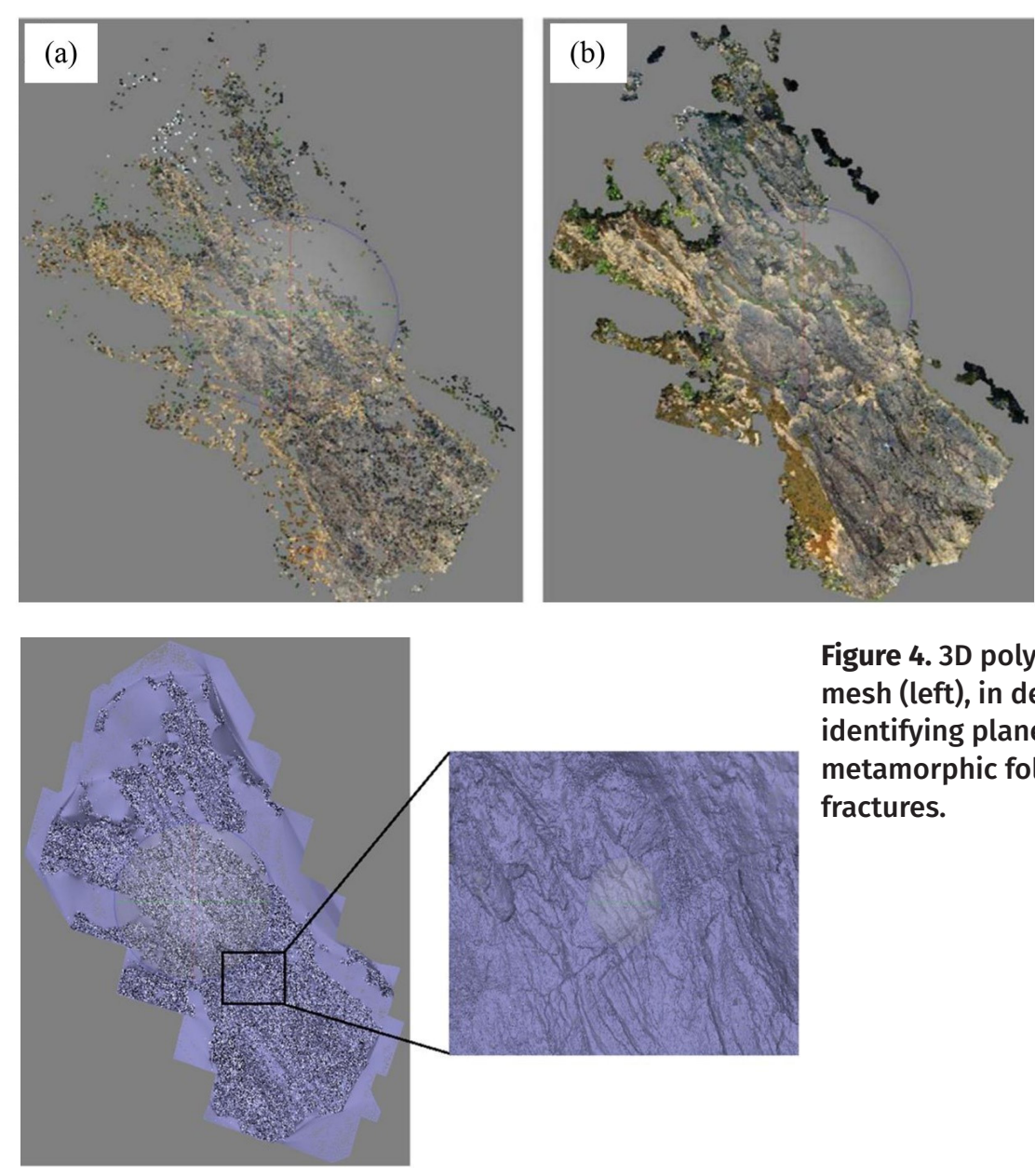

Figure 3. (a) Sparse

cloud of points; (b)

Dense cloud of points.

Figure 4. 3D polygonal

mesh (left), in detail (right),

identifying planes of

metamorphic foliation and

fractures.
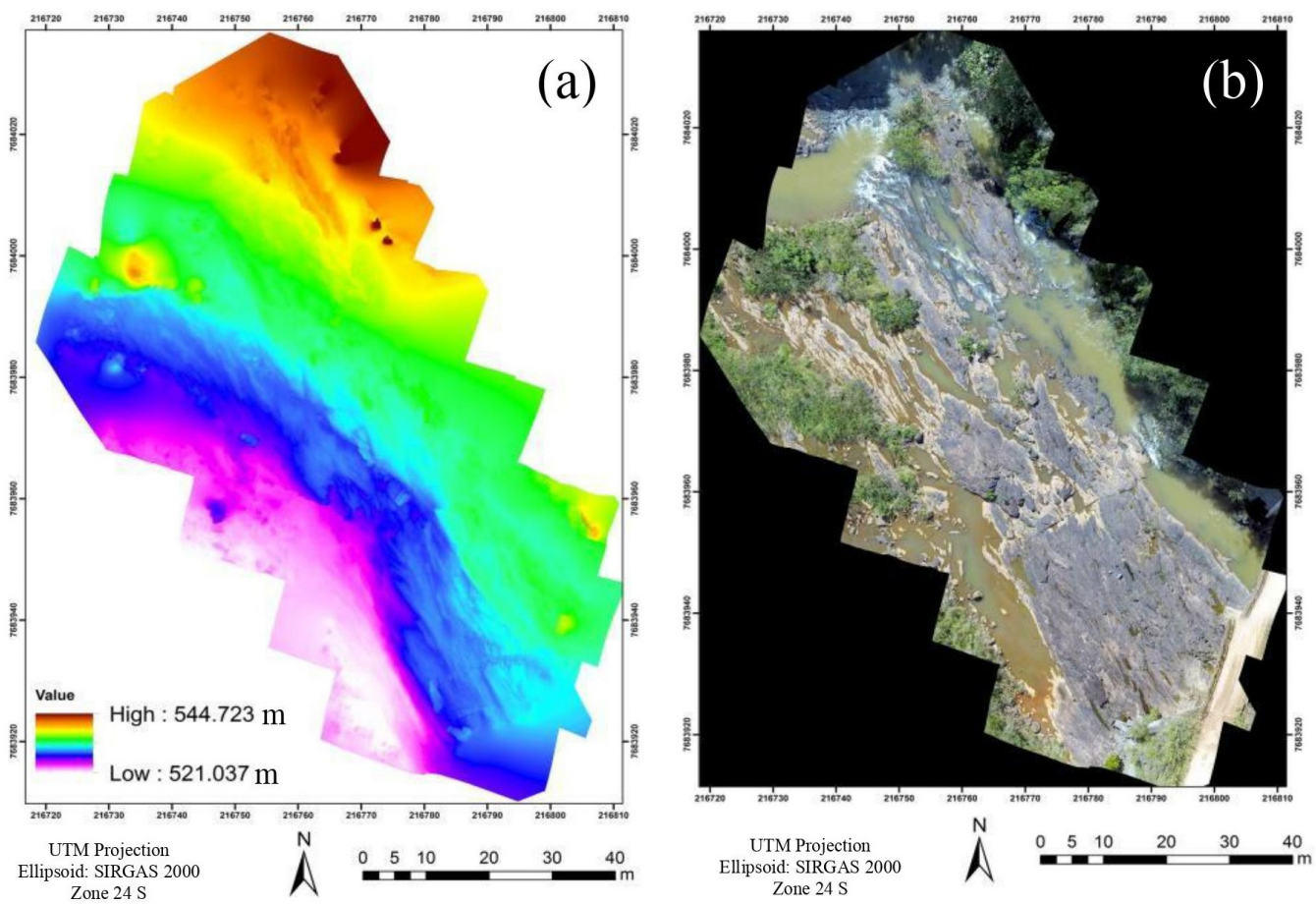

Figure 5. (a)

DME and (b)

Orthomosaic. 

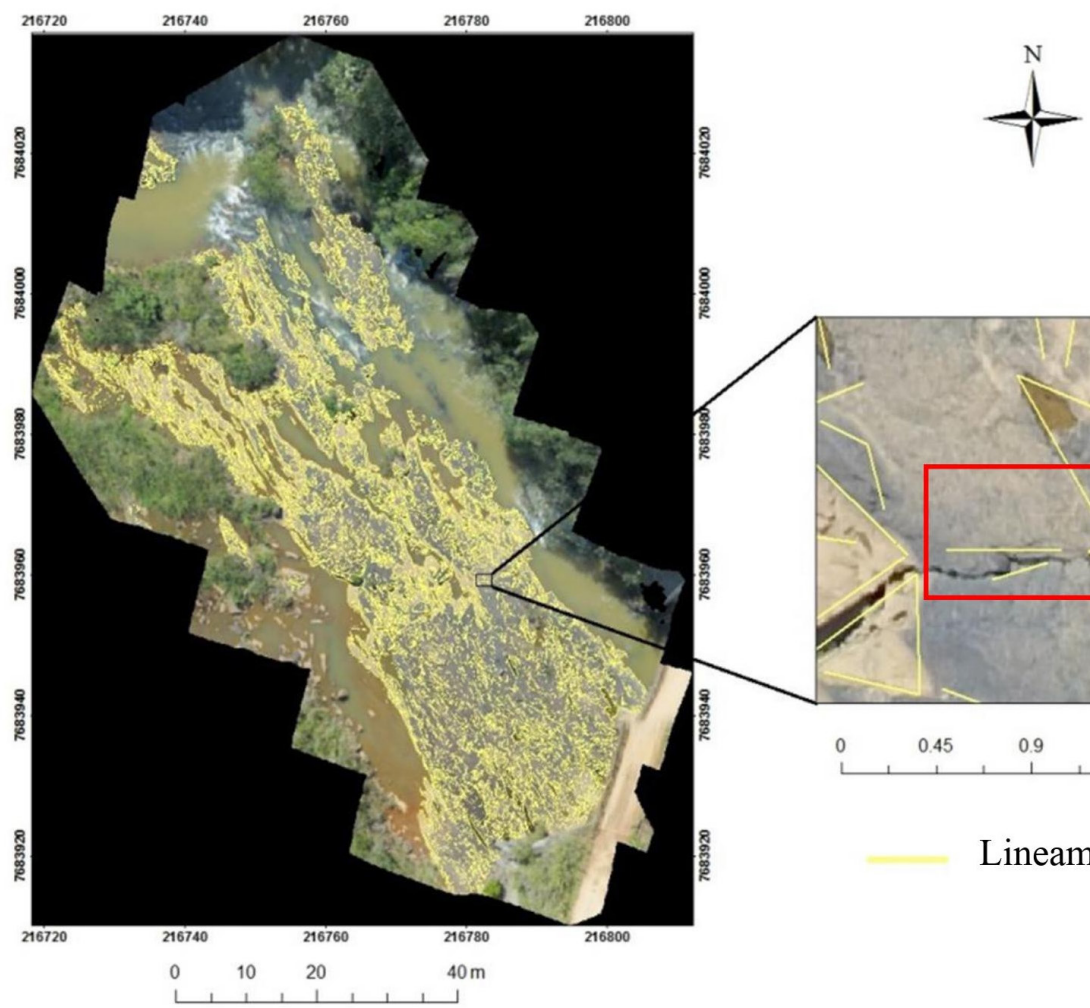

Figure 6.

Orthomosaic with the lineaments extracted by the LINE algorithm (left) and in detail (right), exhibiting a single segmented lineament (red rectangle) in several and the demarcation among tone contrasts like lineament.
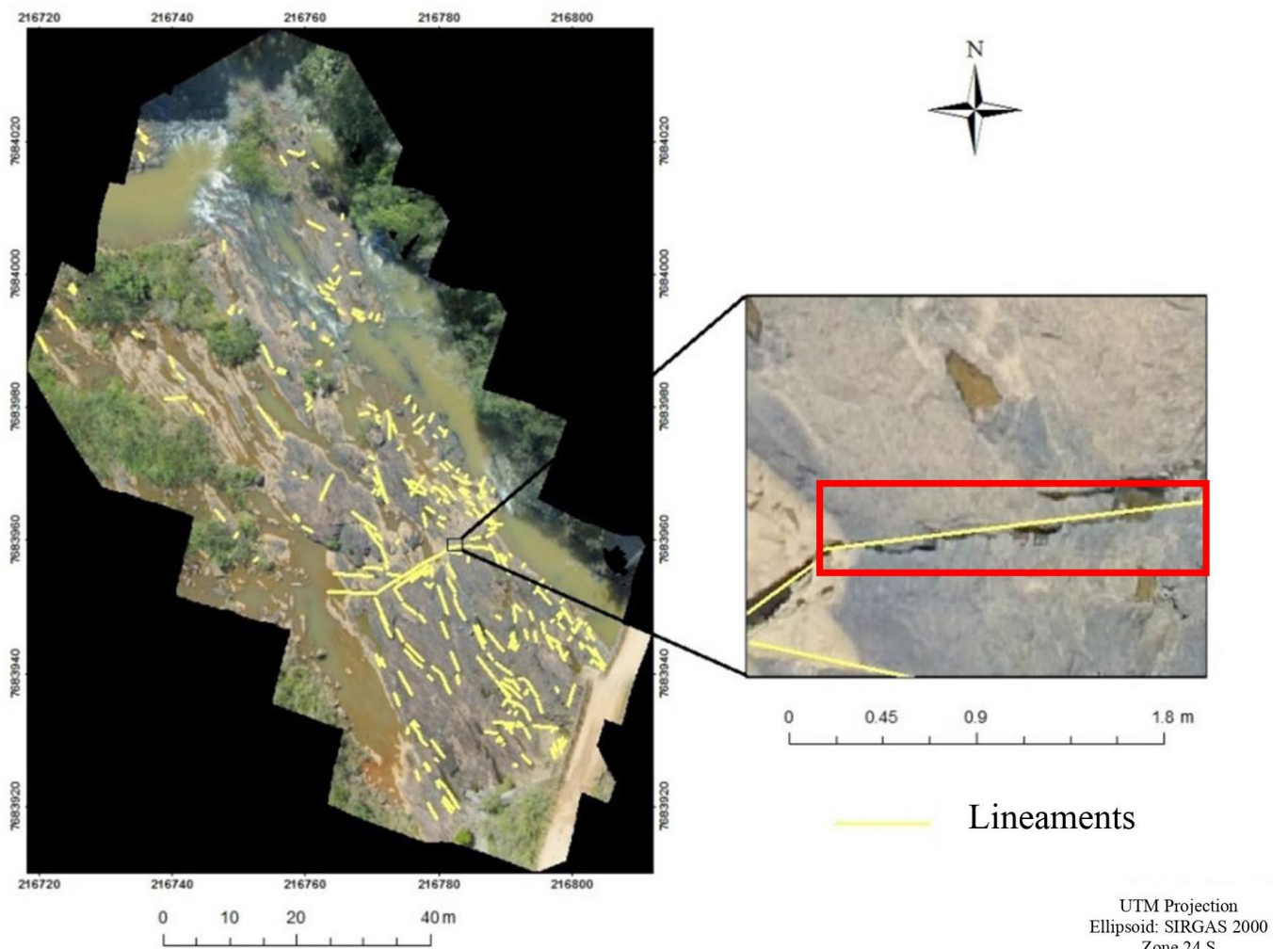

Figure 7.

Orthomosaic with the manually extracted lineaments (left), and in detail (right) illustration of a single lineament (red rectangle), not identified in segmented way. 

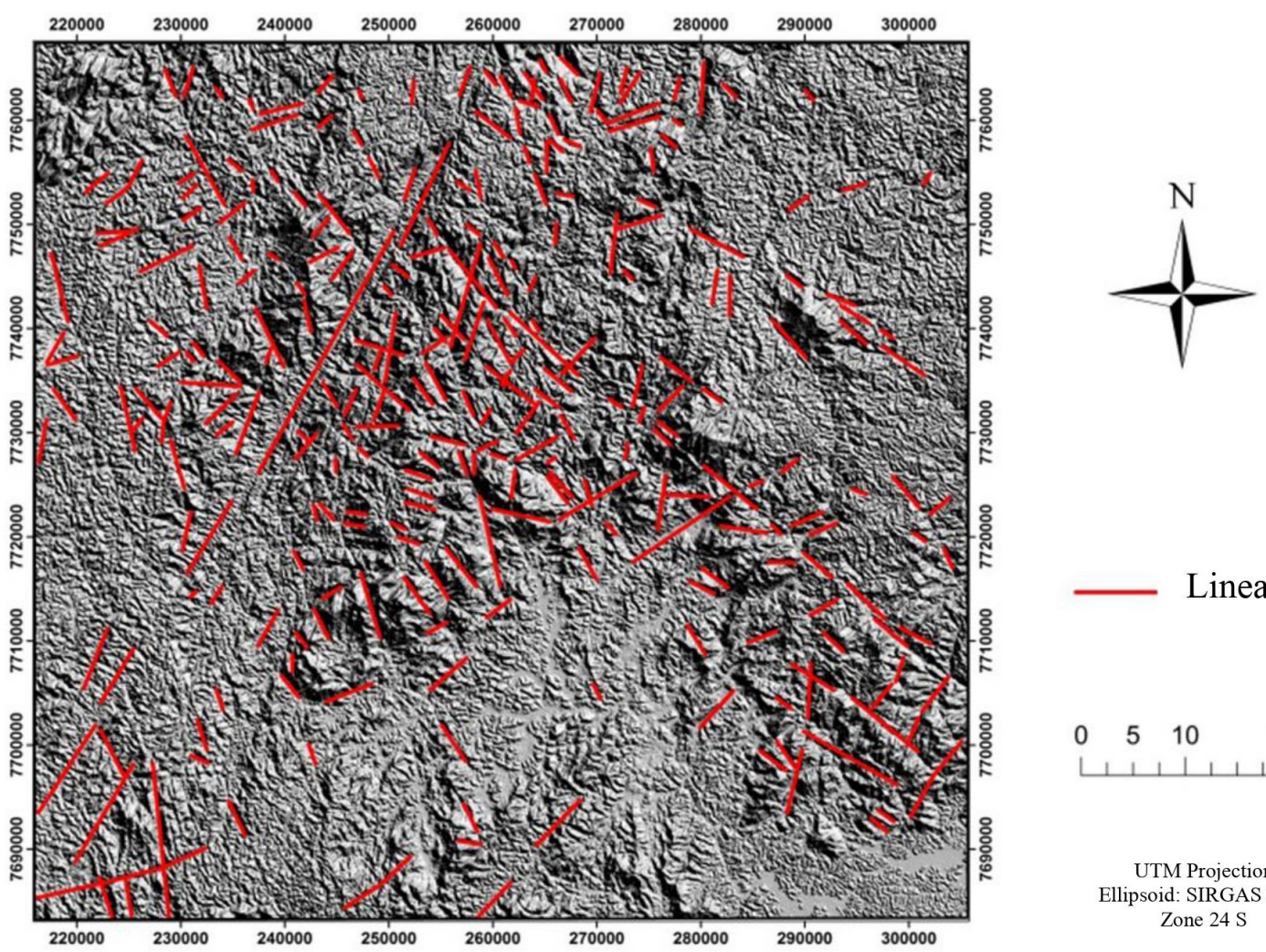

Figure 8. Shaded relief image with azimuth of $135^{\circ}$ /elevation $45^{\circ}$, and its lineaments manually extracted.

NW-SE

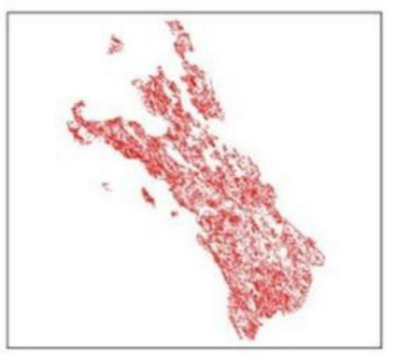

NE-SW

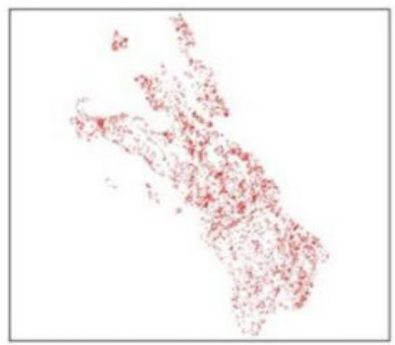

E-W

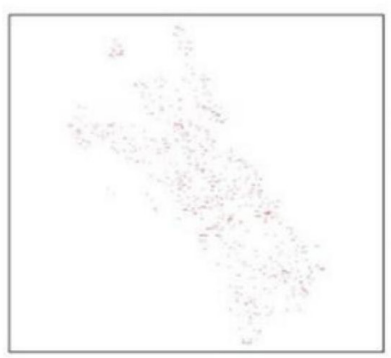

N-S

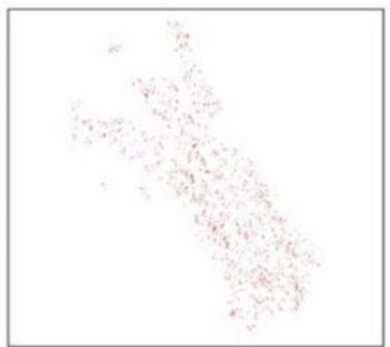

Figure 9.

Directional maps of linears features automatically extracted by the LINE algorithm.

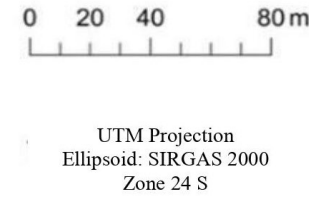


NW-SE

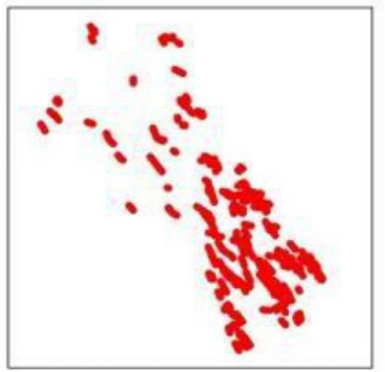

NE-SW

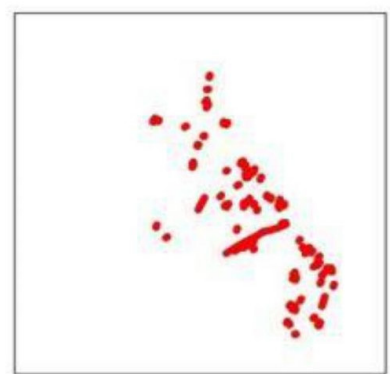

E-W

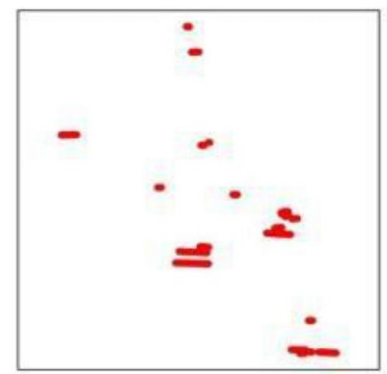

N-S

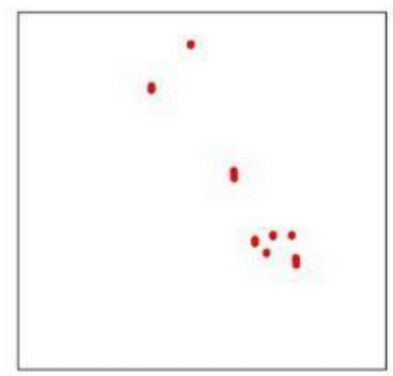

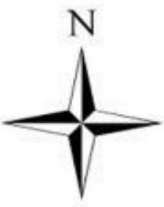

$0 \quad 20 \quad 40 \quad 80 \mathrm{~m}$

UTM Projection Ellipsoid: SIRGAS 2000

Figure 10. Directional maps of linear features manually extracted on the orthomosaic.

NW-SE

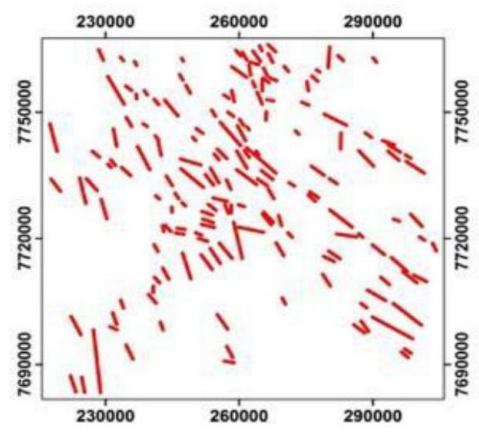

NE-SW

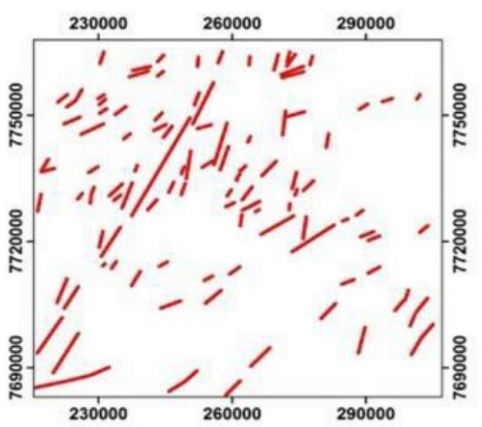

E-W

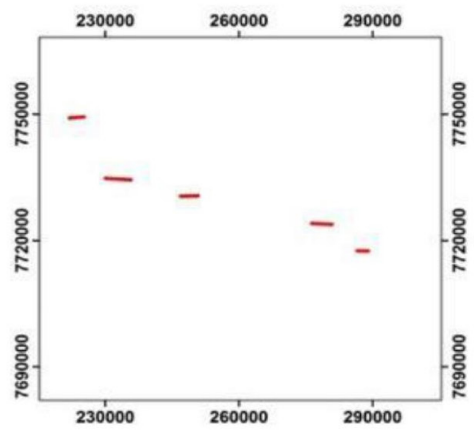

N-S

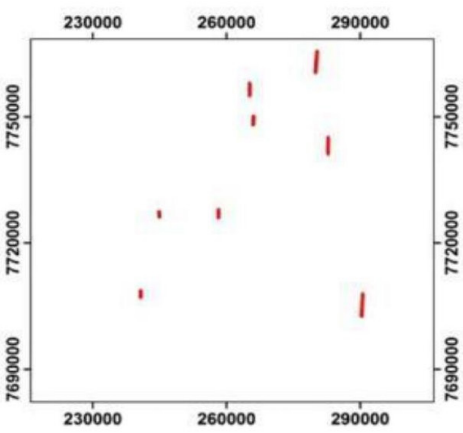

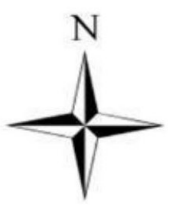

$0 \quad 12.525 \quad 50 \mathrm{~km}$

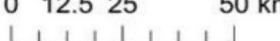

UTM Projection Ellipsoid: SIRGAS 2000 Zone $24 \mathrm{~S}$

Figure 11. Directional maps of linear features manually extracted in the shaded relief image. 
Table III. Statistical analysis of linear features extracted by the LINE algorithm.

\begin{tabular}{|c|c|c|}
\hline Direction & Amount & Percentage (\%) \\
\hline NW-SE & 11,695 & 61.30 \\
\hline NE-SW & 5,599 & 29.35 \\
\hline N-S & 1,106 & 5.80 \\
\hline E-W & 679 & 3.55 \\
\hline
\end{tabular}

Table V. Statistical analysis of linear features manually extracted manually in the shaded relief image.

\begin{tabular}{|c|c|c|}
\hline Direction & Amount & Percentage (\%) \\
\hline NW-SE & 175 & 57.38 \\
\hline NE-SW & 116 & 38.03 \\
\hline N-S & 9 & 2.95 \\
\hline E-W & 5 & 1.64 \\
\hline
\end{tabular}

explained by the fact that the LINE algorithm is based on edge identification, still not having a pattern to distinguish linear features associated to geological structures from the ones that result from the abrupt tonality difference. In addition, sometimes, the algorithm separates the lineament in several line segments, that in truth would be a single one, raising even more the amount of extracted lineaments. On the manual extraction of lineaments from the same orthomosaic, it was generated a total of 318 lineaments (Figure 7), a lower number that can be explained by the fact that the problems mentioned above do not happen, although with a realization time way higher. On the shaded relief image, it was extracted 305 lineaments on total (Figure 8).

From the extracted linear features, it was generated directional maps of the automatically extracted features (Figure 9) and manually
Table IV. Statistical analysis of linear features manually extracted manually on the orthomosaic.

\begin{tabular}{|c|c|c|}
\hline Direction & Amount & Percentage (\%) \\
\hline NW-SE & 196 & 61.63 \\
\hline NE-SW & 91 & 28.62 \\
\hline N-S & 8 & 2.52 \\
\hline E-W & 23 & 7.23 \\
\hline
\end{tabular}

on the orthomosaic (Figure 10), and manually on the shaded relief image (Figure 11). The direction NW-SE was dominant, with $61.30 \%$ (Table III), 61.63\% (Table IV) and 57.38\% (Table $\mathrm{V}$ ), respectively, followed by the direction NE-SW, in every image, revealing the strong correlation among all of them, as much locally between two tested methods on the orthomosaic, as regionally from the data of the shaded relief image. The linear features extracted from the orthomosaic generated by UAV such as manually as automatically, had directions between N20W and N40W its lineaments predominance (Figure $12 \mathrm{a}, \mathrm{b})$, different from the regional image in which the direction between N50W and N60W was the predominant (Figure 12C), still with high rate of lineament with direction between N20W and N40W. 

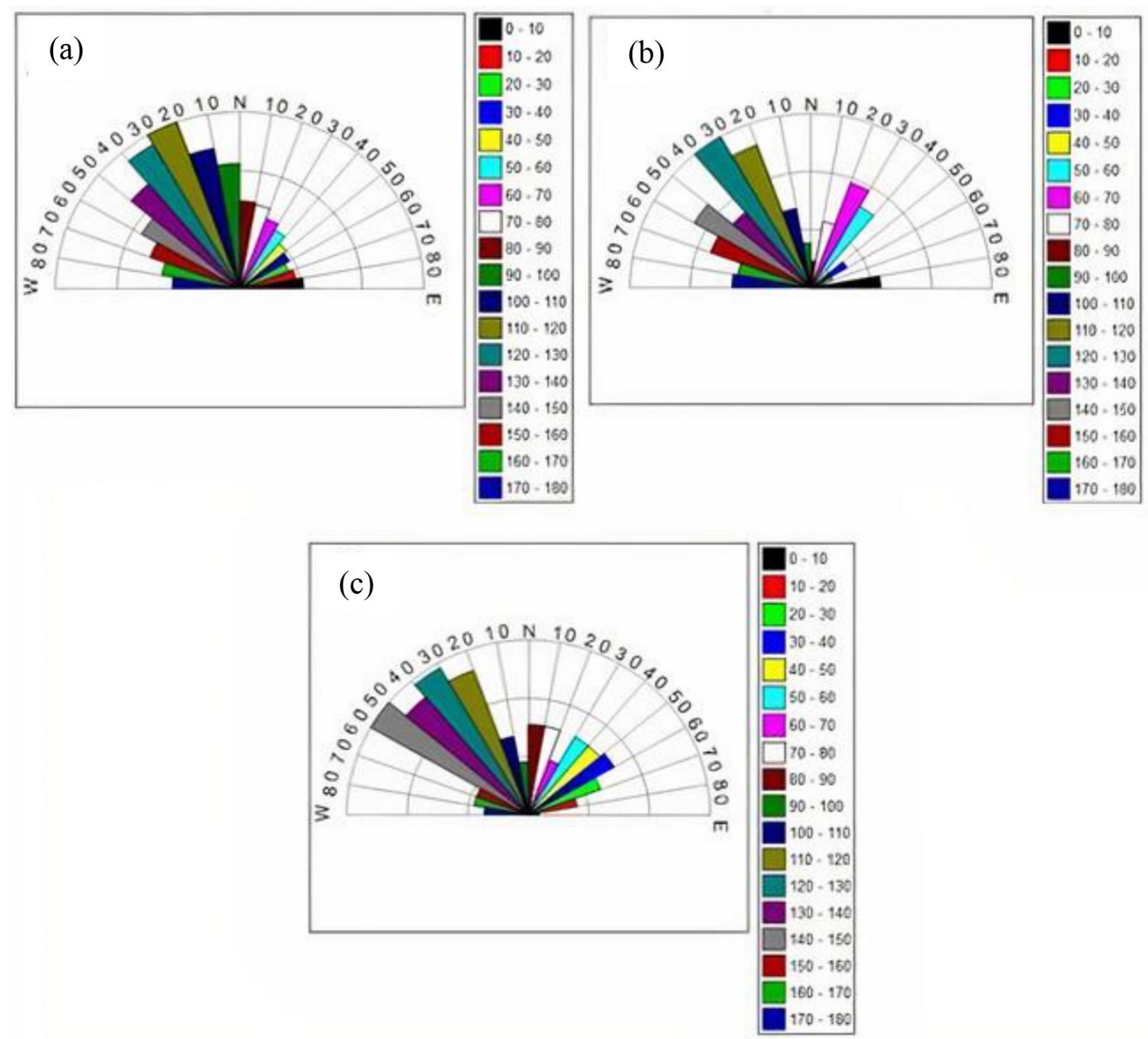

Figure 12. Rosette diagrams of absolute frequency of the linear features extracted (a) automatically on the orthomosaic generated by UAV; (b) manually on the orthomosaic generated by UAV; (c) manually in the shaded relief image.

\section{CONCLUSIONS}

The semi-automatic extraction of lineaments through the orthomosaic generated by UAV using the LINE algorithm proved to be extremely effective on the acquisition of structural trends, since there was a difference of only $0.33 \%$ on the amount of lineaments on the main direction (NW-SE), when compared to the lineaments manually extracted. In a regional scale, these data also substantially correlate when analyzed with the shaded relief SRTM image, in which was also obtained NW-SE as main direction.

The method was not effective on the quantification of these lineaments, due to extracting non geological lineaments and divides a singular linear feature in various ones. Therefore, it is suggested the use of more sophisticated algorithms, like the one tested by Vasuki et al. (2014), in which connection routines of these segmented lineaments are included in 
its scope. That algorithm is not yet available for use.

The fact that the characterization of the area structural control had expressively revealed itself to NW-SE shows the need for new fields of study, since it is not mentioned in literature. It can be explained in this work, that since it was extracted fractures/ faults from it on the orthomosaic generated by UAV and valleys on the shaded relief images, that represent structures formed in brittle regimes and that often do not follow the regional foliation.

The semi-automatic lineament mapping and acquisition of its orientation described in this research can be extremely useful for the structure mapping in areas that are normally considered inaccessible, which includes outdoor mines, mountains, and mostly landslide risk areas, a common problem in Brazil.

\section{Acknowledgments}

The authors thank the Conselho Nacional de Desenvolvimento Científico e Tecnológico (CNPq) (Edital PIBIC 2016/2017) for financial support and scholarship awarded to Julio Almeida Moreira. The authors also thank the Instituto Federal do Espírito Santo (IFES) Campus Guarapari for providing financial support for the translation of the manuscript.

\section{REFERENCES}

ABDULLAH A, NASSR S \& GHALEEB A. 2013. Landsat ETM-7 for lineament mapping using automatic extraction technique in the SW part of Taiz Area, Yemen. Glob Journ of Hum Soc Scien Researc 13: 35-38.

ARCANJO JBA. 2011. Fotogeologia: conceitos, métodos e aplicações. Salvador: CPRM/SBG, 144 p.

ARETOUYAP Z, BILLA L, JONES M \& RICHTER G. 2020. Geospatial and statistical interpretation of lineaments: salinity intrusion in the Kribi-Campo coastland of Cameroon. Adv Space Res 66: 844-853.

CALEGARI SS, NEVES MA, GUADAGNIN F, FRANÇA GS \& VINCENTELLI MGC. 2016. The Alegre Lineament and its role over the tectonic evolution of the Campos Basin and adjacent continental margin, Southeastern Brazil. J S Am Earth Sci 69: 226-242.

CONCEIÇÃO RAC \& SILVA AQ. 2013. Extração automática de lineamentos utilizando imagens SRTM, Landsat ETM+ e ALOS PALSAR na região de Nobres, MT. In: Simpósio Brasileiro de Sensoriamento Remoto/SBSR, 2013, Foz do Iguaçu. Anais XVI Simpósio Brasileiro de Sensoriamento Remoto/SBSR, Foz do Iguaçu: MCT/INPE, p. 3688-3695.

CPRM/SERVIÇO GEOLÓGICO DO BRASIL. 2017. Glossário Geológico Ilustrado. Acesso em 01 de agosto de 2017. < http://sigep.cprm.gov.br/glossario/>.

CROMMELINCK S, BENNETT R, GERKE M, NEX F, YANG MY \& VOSSELMAN G. 2016. Review of Automatic Feature Extraction from High-Resolution Optical Sensor Data for UAV-Based Cadastral Mapping. Remote Sens 8: 689.

DAS S, PARDESHI SD, KULKARNI PP \& DOKE A. 2018. Extraction of lineaments from different azimuth angles using geospatial techniques: a case study of Pravara basin, Maharashtra, India. Arab J Geosci 11: 160.

DJI. 2017. Phantom 4. Acesso em 22 de agosto de 2017, <https://www.dji.com/phantom-4/info>.

DONG X, ZHANG Z, YU R, TIAN Q \& ZHU X. 2020. Extraction of Information about Individual Trees from High-SpatialResolution UAV-Acquired Images of an Orchard. Remote Sens 12: 133.

GOUVÊA LP, MEDEIROS SR, MENDES JC, SOARES C, MARQUES R \& MELO M. 2020. Magmatic activity period and estimation of P-T metamorphic conditions of pre-collisional opxmetatonalite from Araçuaí-Ribeira orogens boundary, SE Brazil. J S Am Earth Sci 99: 102506.

HARTWIG ME, MELO MG \& MOREIRA CA. 2020. Structure and tectonic significance of high- and low-temperature deformation along the lateral escape-related Guaçuí and Batatal shear zones, southern Araçuaí Orogen (southeastern Brazil). REM-Rev Esc Minas 73: 499-512.

JAVHAR A, CHEN X, BAO A, JAMSHED A, YUNUS M, JOVID A \& LATIPA T. 2019. Comparison of Multi-Resolution Optical Landsat-8, Sentinel-2 and Radar Sentinel-1 Data for Automatic Lineament Extraction: A Case Study of Alichur Area, SE Pamir. Remote Sens 11: 778.

JIANG S, JIANG C \& JIANG W. 2020. Efficient structure from motion for large-scale UAV images: A review and a comparison of SfM tools. ISPRS J Photogramm 167: 230-251.

KARANTANELLIS E, MARINOS V, VASSILAKIS E \& CHRISTARAS B. 2020. Object-Based Analysis Using Unmanned Aerial Vehicles (UAVS) for Site-Specific Landslide Assessment. Remote Sens 12: 1711. 
KOCAL A, DUZGUN HS \& KARPUZ C. 2004. Discontinuity Mapping With Automatic Lineament Extraction from High Resolution Satellite Imagery. Int Arch Photogramm Remote Sens Spat Inf Sci-ISPRS Arch 35: 1073-1078.

RAJ NJ, PRABHAKARAN A \& MUTHUKRISHNAN A. 2017. Extraction and analysis of geological lineaments of Kolli hills, Tamil Nadu: a study using remote sensing and GIS. Arab J Geosci 10: 195.

SARP G. 2005. Lineament analysis from satellite images, northeast of Ankara. Tese (Mestrado). Ankara: School of Natural and Applied Science, Middle East Technical University. (Unpublished).

SHARIFI A, MALIAN A \& SOLTANI A. 2018. Efficiency Evaluating of Automatic Lineament Extraction by Means of Remote Sensing (Case Study: Venarch, Iran). J Indian Soc Remote 46: 1507-1518.

SILVA CA, DUARTE CR, SOUTO MVS, SANTOS ALS, AMARO VE, BICHO CP \& SABADIA JAB. 2016. Avaliação da acurácia do cálculo de volume de pilhas de rejeito utilizando VANT, GNSS e LiDAR. Bol Ciênc Geod 22: 73-94.

SNAVELY N, SEITZ SM \& SZELISKI R. 2007. Modeling the world from internet photo collections. Intern Journ of Comp Vis 80: 189-210.

SOLIMAN A \& HAN L. 2019. Effects of vertical accuracy of digital elevation model (DEM) data on automatic lineaments extraction from shaded DEM. Adv Space Res 64: 603-622.

THANNOUN RG. 2013. Automatic Extraction and Geospatial Analysis of Lineaments and their tectonic significance in some areas of Northern Iraq using remote sensing techniques and GIS. Intern Journ of Enhanc Researc in Scien Techno and Engineer 2: 1-11.

USGS/ UNITED STATES GEOLOGICAL SURVEY. 2017. EarthExplorer. Acesso em: 22 de agosto de 2017. <https://earthexplorer. usgs.gov/>.

VASUKI Y, HOLDEN E, KOVESI P \& MICKLETHWAITE E. 2014. Semi-automatic mapping of geological Structures using UAV-based photogrammetric data: An image analysis approach. Comput \& Geosc 69: 22-32.

ZHAO Y, CHEN N, CHEN J \& HU C. 2018. Automatic extraction of yardangs using Landsat 8 and UAV images: A case study in the Qaidam Basin, China. Aeolian Res 33: 53-61.
Manuscript received on November 18, 2019; accepted for publication on January 23, 2021

\section{JULIO A. MOREIRA 1}

https://orcid.org/0000-0002-7780-8679

\section{FABRICIA B. DE OLIVEIRA ${ }^{1}$}

https://orcid.org/0000-0002-4456-0275

\section{CARLOS H.R. DE OLIVEIRA ${ }^{2}$}

https://orcid.org/0000-0003-4829-8005

\section{ALVARO C. FIGUEIREDO ${ }^{1}$}

https://orcid.org/0000-0001-8549-9063

\section{MAURO C.L. FILHO ${ }^{1}$}

https://orcid.org/0000-0002-3279-2706

\section{EDUARDO B. DUARTE ${ }^{3}$}

https://orcid.org/0000-0003-0023-7350

${ }^{1}$ Universidade Federal do Espírito Santo, Centro de Ciências Exatas Naturais e da Saúde, Departamento de Geologia, Alto Universitário, s/n, Guararema, 29500-000 Alegre, ES, Brazil

${ }^{2}$ Direção de Pesquisa, Extensão e Pós-Graduação, Instituto Federal do Espírito Santo, Av. 7 de Novembro, 40, Centro, 29395-000 Ibatiba, ES, Brazil

${ }^{3}$ Programa de Pós-Graduação em Agroquímica, Universidade Federal do Espírito Santo, Centro de Ciências Exatas Naturais e da Saúde, Alto Universitário, s/n, Guararema, 29500-000 Alegre, ES, Brazil

Correspondence to: Eduardo Baudson Duarte E-mail: eduardo_duarte_12@hotmail.com

\section{Author contributions}

Julio Almeida Moreira: Proposed the study, data acquisition, analysis and interpretation; Fabricia Benda de Oliveira: Guidance, data analysis and interpretation; Carlos Henrique Rodrigues de Oliveira: Data acquisition, analysis and interpretation; Alvaro Costa Figueiredo, Mauro de Castro Lima Filho and Eduardo Baudson Duarte: Data analysis and interpretation.

\section{How to cite}

MOREIRA JA, DE OLIVEIRA FB, DE OLIVEIRA CHR, FIGUEIREDO AC, FILHO MCL \& DUARTE EB. 2021. High-resolution semi-automatic mapping based on an Unmanned Aerial Vehicle (UAV) to capture geological structures. An Acad Bras Cienc 93: e20191416. DOI 10.1590/0001-3765202120191416. 